\title{
MXenes Atomic Layer Stacking Phase Transitions and their Chemical Activity Consequences
}

\author{
José D. Gouveia ${ }^{1}$, Francesc Viñes, ${ }^{2 *}$ Francesc Illas, ${ }^{2}$ José R. B. Gomes ${ }^{1 *}$ \\ ${ }^{I}$ CICECO - Aveiro Institute of Materials, Department of Chemistry, University of Aveiro, \\ Campus Universitário de Santiago, Aveiro, Portugal \\ ${ }^{2}$ Departament de Ciència de Materials i Química Física \& Institut de Química Teòrica i \\ Computacional (IQTCUB), Universitat de Barcelona, c/ Martí i Franquès 1-11, 08028
}

Barcelona, Spain

Corresponding authors: jrgomes@ua.pt; francesc.vines@ub.edu

\begin{abstract}
Two-dimensional (2D) transition-metal nitrides and carbides (MXenes), containing a few atomic layers only, are novel materials which have become a hub of research in many applied technological fields, ranging from catalysis, to environmental scrubber materials, up to batteries. MXenes are obtained by removing the A element from precursor MAX phases, and it is for this reason that it is often assumed that the resulting $2 \mathrm{D}$ material displays the MAX atomic layer stacking - an $\mathrm{ABC}$ sequence with trigonal $\left(D_{3 \mathrm{~d}}\right)$ symmetry. By means of density functional theory based calculations, including dispersion, the present work thoroughly explores the stability of alternative ABA stacking, with $D_{3 \mathrm{~h}}$ hexagonal symmetry, for a total of 54 MXene materials with $\mathrm{M}_{2} \mathrm{X}, \mathrm{M}_{3} \mathrm{X}_{2}$, and $\mathrm{M}_{4} \mathrm{X}_{3}$ stoichiometries $(\mathrm{M}=\mathrm{Ti}, \mathrm{Zr}, \mathrm{Hf}, \mathrm{V}, \mathrm{Nb}, \mathrm{Ta}, \mathrm{Cr}$, Mo, or $\mathrm{W}$; and $\mathrm{X}=\mathrm{C}$ or $\mathrm{N}$ ), revealing that for clean MXenes, the ABA stacking is fostered $i$ ) by the number of $d$ electrons of the transition metal, $i i)$ when the MXene is a nitride rather than a carbide, and iii) when the MXene surface is terminated by oxygen adatoms. The present results suggest that stacking phase transitions are likely to take place under working operando conditions, surmounting affordable layer sliding energy barriers, in accordance to the experimentally observed layer distortions found in $\mathrm{Mo}_{2} \mathrm{~N}$. Finally, we tackle the adsorptive and catalytic capabilities implications of such a layer phase transition by considering $\mathrm{N}_{2}$ adsorption, dissociation, and hydrogenation on selected $\mathrm{ABC}$ and $\mathrm{ABA}$ stacked MXenes. Results highlight changes in adsorption energies of up to $\sim 1 \mathrm{eV}$, and in $\mathrm{N}_{2}$ dissociation energy barriers of up to $\sim 0.3 \mathrm{eV}$, which can critically change the reaction step rate constant by three to four orders of magnitude for working temperatures in the 400-700 K range. Consequently, the present results highlight the need of carefully determining the atomic structure of MXenes and to use models with the most stable stacking when inspecting their chemical or physical properties.
\end{abstract}




\section{Introduction}

Recently, a new class of two-dimensional (2D) materials was discovered by Naguib et al. [1] These materials, called MXenes, exhibit high electrical conductivity, hydrophilicity, large surface area, tunable structure, and superior oxidation resistance, among many other properties [2]. Not surprisingly, applications based on MXenes are gaining momentum in areas such as ecofriendly energy [3], greenhouse gases scrubber materials [4,5], batteries [6], water purification [7-9], or heterogeneous catalysis [10], among many other fields of technological applicability. MXenes are usually obtained by selective etching - typically with hydrofluoric acid, HF - of the A element from a precursor MAX phase [11-13]; where M is usually an early transition metal - e.g. Ti, Zr, Hf, V, Nb, Ta, Cr, Mo, W-, the A element belongs to a subset of groups XII-XVI of the periodic table, and X is carbon and/or nitrogen [14]. In general, MXenes have $n+1$ layers of hexagonal close-packed transition metals intercalated by $n$ layers of hexagonal close-packed $\mathrm{C}$ or $\mathrm{N}$ atoms, with a face-centered cubic $(f c c)$-i.e. $\mathrm{ABC}$ - stacking, and $n=1-3$. As a result of the synthesis procedure [1], MXenes feature a surface termination, usually denoted as $T_{x}$, so that the general formula of MXenes is often expressed as $M_{n+1} X_{n} T_{x}$, where $\mathrm{T}_{\mathrm{x}}$ is in most cases a mixture of $-\mathrm{OH},-\mathrm{O},-\mathrm{H}$, or $-\mathrm{F}$ moieties. Nevertheless, the progress in this field evolves very rapidly and recent HF-free syntheses have been reported yielding MXenes terminated by $\mathrm{H}$ and $\mathrm{OH}$ only $[15,16]$, or upon fine tuning the layer sequence, reaching thicker $n=5$ MXenes, with a central metal layer different from the other ones [17]. Also, even post-synthesis annealing and hydrogenation protocols have been developed to successfully defunctionalize MXene surfaces [5], thus modifying their properties by increasing their electrical conductivity [18].

While MXene surfaces are highly reactive, their atomic structure remains virtually unchanged in the presence of an adsorbate, yet some oddities have been found to occur. For instance, Shao et al. [19] predicted that $\mathrm{Mo}_{2} \mathrm{~N}$ and $\mathrm{W}_{2} \mathrm{~N}$ MXenes become structurally distorted upon adsorbing a nitrogen molecule, a feature that is observed as well on $\mathrm{W}_{2} \mathrm{C}$ and $\mathrm{Cr}_{2} \mathrm{~N}$. In a recent synthesis and characterization study, $\mathrm{V}_{2} \mathrm{~N}$ and $\mathrm{Mo}_{2} \mathrm{~N}$ MXenes were produced by ammonia treatment of the parent carbides [20]. There, the hexagonal phase of $\mathrm{V}_{2} \mathrm{~N}$ displayed the usual trigonal $D_{3 \mathrm{~d}}$ symmetry of MXenes $-f c c \mathrm{ABC}$ stacking-, but the resulting $\mathrm{Mo}_{2} \mathrm{~N}$ sample was described as having a distorted structure with hexagonal close-packed $(h c p) D_{3 \mathrm{~h}}$ symmetry -ABA stacking. Given the above subtlety, one may wonder if MXene stacking structures other than $f c c$ exist, and whether the transformation from $\mathrm{ABC}$ to $\mathrm{ABA}$ is intrinsic or can be prompted by either the $T_{x}$ termination, as suggested on $\mathrm{M}_{2} \mathrm{X}$ MXenes with ABA stacking when having $\mathrm{O}$ termination , aka BiXenes [21], or by the presence of an adsorbate. Both sources of restacking may indeed bestow a symmetry change, eventually translatable into a lowering of the stacking conversion energy barrier, and, ultimately, prompting a stacking phase transition. 
Structural stacking changes may well imply different chemical surface activity, a point than can be key in chemically enhanced few-layered materials. Therefore, information on the preferred stacking of MXenes under working conditions is mandatory to guide future research on the field. However, obtaining this information requires investigating these materials at an inherent atomic level, an aspect difficult to be realized experimentally. Here, motivated by the aforementioned evidence indicating structural distortions and the existence of alternative stackings $[19,20]$, we employ complete and accurate Density Functional Theory (DFT) simulations on suited MXene models to systematically analyze the stability of the ABA stacking relative to the usual $\mathrm{ABC}$ one. Thus, we consider a wide, organized set of MXenes encompassing different widths, inspecting both thermodynamic and kinetic aspects of the structural conversion. Although the study is mainly focused on pristine MXenes, the possible effect of surface termination on the stability of ABA stacking and/or its conversion is also addressed by considering $\mathrm{T}_{\mathrm{x}}=\mathrm{O}$ termination, and building oxygen-coverage phase diagrams. Finally, the effect of the ABA stacking on the surface chemical activity of the MXenes is analyzed addressing the textbook $\mathrm{N}_{2}$ adsorption and dissociation steps, key in the technologically relevant Haber-Bosch process of ammonia synthesis [22].

\section{Computational details}

The present study relies on DFT-based first-principles calculations using the Vienna Ab initio Simulation Package (VASP) [23], carried out on suitable MXene periodic slab models. The calculations were performed within the generalized gradient approximation to the many-body exchange-correlation potential, namely, using the functional developed by Perdew, Burke, and Ernzerhof $(P B E)$ [24], augmented with the Grimme D3 method to account for dispersive forces [25]. The valence electron density was expanded in plane-wave basis sets and the Projector Augmented Wave (PAW) method [26] was used to describe the effect of the atomic cores on the valence electronic density. The cutoff for the kinetic energy of the plane waves was set to 415 $\mathrm{eV}$ although a higher value of $550 \mathrm{eV}$ was used for the calculation of lattice constants. The convergence criteria for the self-consistent energies and forces on the relaxed structures were set to $10^{-6} \mathrm{eV}$ and $0.01 \mathrm{eV} \cdot \AA^{-1}$, respectively.

The MXenes studied in the present work were modeled by hexagonal $p(3 \times 3)$ periodic supercells containing 9 atoms per layer, see Figure 1. In order to avoid interaction between MXene replicas due to periodic boundary conditions in the direction perpendicular to the surface, a vacuum region of at least $10 \AA$ was set between periodic copies, both when the

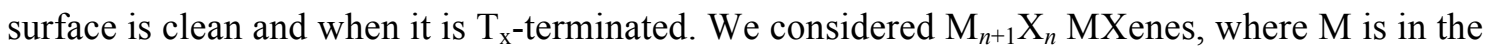
$\mathrm{Ti}, \mathrm{Zr}, \mathrm{Hf}, \mathrm{V}, \mathrm{Nb}, \mathrm{Ta}, \mathrm{Cr}, \mathrm{Mo}, \mathrm{W}$ list, $\mathrm{X}$ is $\mathrm{C}$ or $\mathrm{N}$, and $n=1-3$. Only two limit regular stacking possibilities - $\mathrm{ABC}$ and $\mathrm{ABA}$ - were initially considered, regardless of the MXene width, and 
thus, neglecting other possible mixed situations, see Figure 1. The calculated lattice parameters, $a$, for the ABC-stacked lattices are in consonance with those reported in the literature [27,28], see Table 1, while the change in $a$ for $n \geq 2$ was found to be lower than $1 \%$; thus, the same lattice constant was used regardless of the MXene thickness. The lattice constants of the ABAstacked surfaces, however, can vary up to $8 \%$ with respect to the $\mathrm{ABC}$ situation, the former being smaller than the latter, with the exception of $\mathrm{Mo}_{2} \mathrm{~N}$. For example, the calculated lattice parameters for $\mathrm{ABC}$ - and $\mathrm{ABA}$-stacked $\mathrm{Mo}_{2} \mathrm{C}$ are $3.10 \AA$ and $2.84 \AA$, respectively, in very good agreement with the corresponding values reported by Sun et al. of 3.06 and $2.88 \AA$, respectively [29]. The differences in lattice parameter for each stacking are crucial to obtain accurate, reliable and physically meaningful results, both quantitative and qualitative. Using the example of $\mathrm{Mo}_{2} \mathrm{C}$ as a test case, when one uses the same lattice parameter for both stackings, one finds that $\mathrm{ABC}$ is more stable, by $0.59 \mathrm{eV}$ per formula unit, while the usage of the proper lattice parameters for each stacking phase yields instead a preference for ABA stacking, by $0.29 \mathrm{eV}$ per formula unit, in very good agreement with previous estimates [29]. The reciprocal space Brillouin zone was sampled using a Monkhorst-Pack $5 \times 5 \times 1$ grid of special k-points [30]. Convergence tests on k-point density and basis set size showed that calculations have a numerical accuracy of about $1 \mathrm{meV}$ per atom. Preliminary tests also showed that spin polarization is required in order to obtain correct total energies for $\mathrm{Ti}_{2} \mathrm{C}, \mathrm{Zr}_{2} \mathrm{C}$, and $\mathrm{Cr}_{2} \mathrm{C}$, regardless of their stacking. The saddle-point configurations of the minimum-energy pathways for layer realignments were located via the dimer method [31].
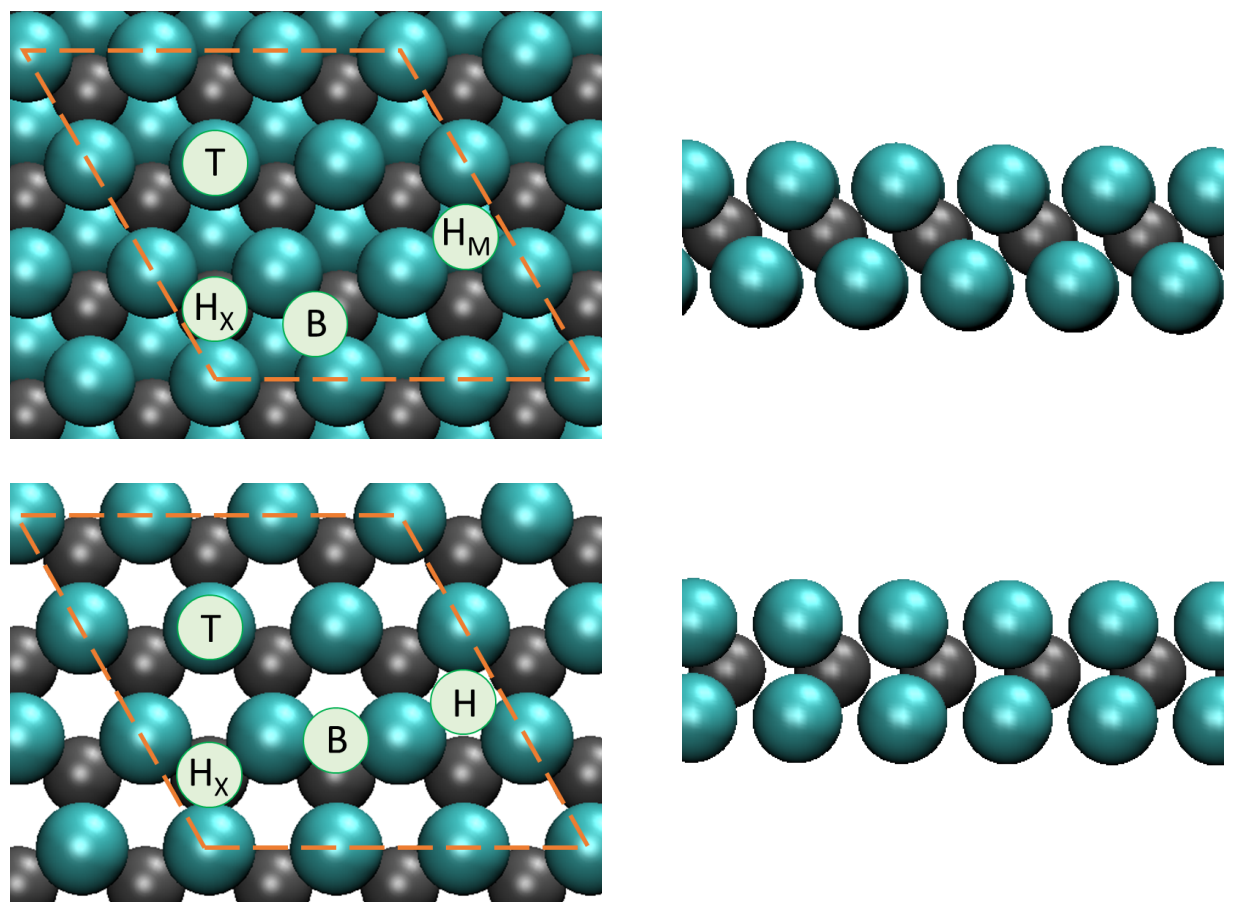

Figure 1. Top (left panels) and side (right panels) views of a $p(3 \times 3) \mathrm{M}_{2} \mathrm{X}$ supercell. The top images represent $\mathrm{ABC}$ stacking, while bottom ones feature $\mathrm{ABA}$ stacking. Green (grey) spheres 
denote $\mathrm{M}(\mathrm{X})$ atoms. Tags are shown for high-symmetry relevant surface sites, including bridge (B), top $(\mathrm{T})$, hollow $(\mathrm{H})$, hollow metal $\left(\mathrm{H}_{\mathrm{M}}\right)$, and hollow carbon/nitrogen $\left(\mathrm{H}_{\mathrm{X}}\right.$, in practice $\mathrm{H}_{\mathrm{C}}$ or $\mathrm{H}_{\mathrm{N}}$ ) positions. The dashed orange rhombus represents the boundaries of the periodic supercell.

Table 1. Calculated lattice parameters, $a$, in $\AA$, for the studied MXenes with ABC (ABA) stacking. Values are given for $\mathrm{M}_{2} \mathrm{X}$ MXenes, as they are equivalent for cases with larger $n$.

\begin{tabular}{ccc}
\hline $\boldsymbol{a}$ & $\boldsymbol{C}$ & $\boldsymbol{N}$ \\
\hline \hline $\mathrm{Ti}$ & $3.06(3.00)$ & $2.98(2.86)$ \\
$\mathrm{Zr}$ & $3.27(3.23)$ & $3.24(3.08)$ \\
$\mathrm{Hf}$ & $3.21(3.16)$ & $3.17(3.04)$ \\
$\mathrm{V}$ & $2.90(2.76)$ & $2.89(2.67)$ \\
$\mathrm{Nb}$ & $3.13(2.94)$ & $3.15(2.90)$ \\
$\mathrm{Ta}$ & $3.09(2.94)$ & $3.09(2.88)$ \\
$\mathrm{Cr}$ & $2.82(2.62)$ & $2.68(2.61)$ \\
$\mathrm{Mo}$ & $3.10(2.84)$ & $2.79(2.82)$ \\
$\mathrm{W}$ & $2.88(2.84)$ & $2.78(2.78)$ \\
\hline
\end{tabular}

To take into account the effect of termination, we consider the particular case of oxygen. To this end, the $\mathrm{O}_{2}$ partial pressure, $p_{\mathrm{O}_{2}}$, vs. temperature, $T$, phase diagrams were built by terminating one MXene surface side by $\mathrm{O}$ adatoms, and calculating for each $T / p_{\mathrm{O}_{2}}$ pair the Gibbs free energy of adsorption, $G_{\text {ads }}$, for a number of $\mathrm{O}$ adatoms, $N_{\mathrm{O}} \in[1,9]$, added on the other MXene surface side, and picking the lowest $G_{\text {ads }}$ for a given coverage as the ground state. The $G_{\text {ads }}$ is calculated as [32]

$$
G_{\mathrm{ads}}\left(T, p_{O_{2}}\right)=E_{\mathrm{ads}}-k_{\mathrm{B}} T \ln \left(\frac{Q_{N_{\mathrm{O}} / \mathrm{MXene}}}{\left(Q_{\mathrm{O}_{2}}\right)^{N_{\mathrm{O}} / 2}}\right)
$$

where $E_{\text {ads }}$ is the simultaneous adsorption energy of $N_{\mathrm{O}}$ oxygen adatoms, including the Zero Point Energy ( $Z P E)$ term, $k_{\mathrm{B}}$ is the Boltzmann constant, $Q_{N_{\mathrm{O}} / \mathrm{MXene}}$ the partition function of the MXene fully terminated by $\mathrm{O}$ on one side, and with $N_{\mathrm{O}} \mathrm{O}$ adatoms on the other side, and $\left(Q_{\mathrm{O}_{2}}\right)^{N_{\mathrm{O}} / 2}$ the partition function of $N_{\mathrm{O}}$ oxygen atoms as in gas phase isolated $\mathrm{O}_{2}$ molecules. The adsorption energy of $N_{\mathrm{O}} \mathrm{O}$ atoms on a MXene surface, including $Z P E$, is

$$
E_{\text {ads }}=\left(E_{N_{\mathrm{O}} / \mathrm{MXene}}+\mathrm{ZPE}_{N_{\mathrm{O}} / \mathrm{MXene}}\right)-E_{\mathrm{MXene}}-\frac{N_{\mathrm{O}}}{2}\left(\mathrm{E}_{\mathrm{O}_{2}}+\mathrm{ZPE}_{\mathrm{O}_{2}}\right)
$$

where $E_{N_{\mathrm{O}} / \text { MXene }}$ is the total energy of the MXene fully terminated by $\mathrm{O}$ on one side and with $N_{\mathrm{O}} \mathrm{O}$ adatoms on the other side, $\mathrm{ZPE}_{N_{\mathrm{O}} / \mathrm{MXene}}$ the corresponding $Z P E$ term involving $3 \cdot N_{\mathrm{O}}$ normal vibrational frequencies, $E_{\mathrm{MXene}}$ the total energy of the MXene fully $\mathrm{O}$ terminated on only one side, $E_{\mathrm{O}_{2}}$ the total energy of an $\mathrm{O}_{2}$ molecule, and $\mathrm{ZPE}_{\mathrm{O}_{2}}$ the $Z P E$ term for its stretching vibrational mode. The $N_{\mathrm{O}} / \mathrm{MXene}$ partition function is 


$$
Q_{N_{\mathrm{O}} / \text { MXene }}=\prod_{i} \frac{1}{1-\exp \left(\frac{-h v_{i}}{2 k_{\mathrm{B}} T}\right)}
$$

where $v_{i}$ are the $3 \cdot N_{\mathrm{O}}$ normal vibrational frequencies of the $N_{\mathrm{O}} \mathrm{O}$ adatoms. The partition function of the $\mathrm{O}_{2}$ molecule in gas phase is the product of vibrational, rotational, and translational contributions, $Q_{\mathrm{O}_{2}}=q_{\mathrm{vib}} \cdot q_{\text {rot }} \cdot q_{\text {trans }}$, where the vibrational contribution is computed in the same way as $Q_{N_{\mathrm{O}}} /$ MXene albeit involving one vibrational frequency only; the rotational partition function is

$$
q_{\mathrm{rot}}=\frac{T}{2 \theta_{\mathrm{O}_{2}}}
$$

where $\theta_{\mathrm{O}_{2}}$ is the rotational temperature of the $\mathrm{O}_{2}$ molecule, calculated from the diagonalization of its inertia tensor, and the translational partition function is

$$
q_{\text {trans }}=\left(\frac{2 \pi m_{\mathrm{O}_{2}} k_{\mathrm{B}} T}{h^{2}}\right)^{3 / 2} \frac{k_{\mathrm{B} T}}{p_{\mathrm{O}_{2}}}
$$

where $m_{\mathrm{O}_{2}}$ is the mass of one $\mathrm{O}_{2}$ molecule.

\section{Results and discussion}

Let us first assess the stability of ABA stacking relative to the $\mathrm{ABC}$ one for the explored 54 MXenes. Table 2 reports the calculated values and Figure 2 provides the corresponding plots of the energy difference per MXene formula unit, $\Delta E_{\text {stack }}=E_{\mathrm{ABA}}-E_{\mathrm{ABC}}$, for $\mathrm{X}=\mathrm{C}, \mathrm{N}$ and for the different $n$ values. Negative values indicate that the ABA stacking is preferred, and values close to zero correspond to near-degeneracy between the two stacking configurations. For the $\mathrm{M}_{2} \mathrm{X}$ stoichiometry $(n=1)$, all group VI MXenes and group $\mathrm{V}$ nitrides but $\mathrm{V}_{2} \mathrm{~N}$ either prefer $\mathrm{ABA}$ stacking or both stackings are found to be nearly equally stable. This prediction is in agreement with experiments indicating that $\mathrm{V}_{2} \mathrm{~N}$ exhibits the $\mathrm{ABC}$ stacking [20]. On the remaining $\mathrm{M}_{2} \mathrm{X}$ surfaces, the $\mathrm{ABC}$ stacking is clearly preferred. Note also that $\Delta E_{\text {stack }}$ is smaller by at least several tenths of $\mathrm{eV}$ on each $\mathrm{M}_{2} \mathrm{~N}$ than on its corresponding $\mathrm{M}_{2} \mathrm{C}$ MXene, with the sole exception of $\mathrm{W}_{2} \mathrm{X}$, where the order of stability is actually reversed. In the case of $\mathrm{M}_{3} \mathrm{X}_{2}(n=2)$ or $\mathrm{M}_{4} \mathrm{X}_{3}(n=3)$ the stacking preferences on group VI are maintained with respect to the thinner MXenes, although ABA stacking becomes the most stable for $\mathrm{V}_{3} \mathrm{~N}_{2}$ and $\mathrm{V}_{4} \mathrm{~N}_{3}$.

For all of the $\mathrm{M} / \mathrm{X}$ combinations, $\Delta E_{\text {stack }}$ appears to vary linearly with $n$. For the $d^{2}$ MXenes and $d^{3}$ carbides, $\Delta E_{\text {stack }}$ increases by circa $1 \mathrm{eV}$ per M-X layer per formula unit, meaning that the addition of more layers further stabilizes the ABC stacking. On the $d^{4}$ MXenes and $d^{3}$ nitrides, the opposite holds, and ABA becomes more stable by an average of around 0.49 eV per formula unit per added layer. The sole exception to this trend are the aforementioned vanadium nitride MXenes, as the $\mathrm{ABC}$ stacking is favored for $\mathrm{V}_{2} \mathrm{~N}$, but $\mathrm{ABA}$ becomes 
stabilized by around $0.26 \mathrm{eV}$ per formula unit per V-N layer, which is enough to change the sign

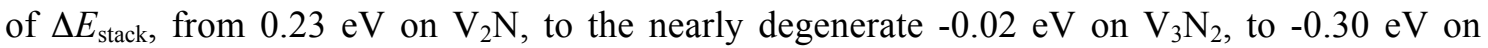
$\mathrm{V}_{4} \mathrm{~N}_{3}$. The $\mathrm{W}_{n+1} \mathrm{C}_{n}$ MXenes display the greatest preference towards ABA, with this stacking becoming $\sim 1 \mathrm{eV}$ more advantageous per formula unit per added $\mathrm{W}-\mathrm{C}$ layer. In summary, the rule of thumb is that each type of MXene releases/absorbs a fixed amount of energy per realigned layer, so that an increase in $n$ usually maintains the stacking preference, reinforcing its energetic preference.

Table 2. Energetic difference per formula unit, $\Delta E_{\text {stack, }}$ in $\mathrm{eV}$, between $\mathrm{ABC}$ and $\mathrm{ABA}$ stacking on all the studied 54 pristine (leftmost numeric columns) or oxygen-terminated (rightmost collumns) MXenes. Bold font indicates energetic preference for ABA stacking, or a nearly degenerate state in between $\mathrm{ABC}$ and $\mathrm{ABA}$.

\begin{tabular}{cc|cccccc}
$\mathbf{X}$ & $\mathbf{M}$ & $\mathbf{M}_{\mathbf{2}} \mathbf{X}$ & $\mathbf{M}_{\mathbf{3}} \mathbf{X}_{\mathbf{2}}$ & $\mathbf{M}_{\mathbf{4}} \mathbf{X}_{\mathbf{3}}$ & $\mathbf{M}_{\mathbf{2}} \mathbf{X} \mathbf{O}_{\mathbf{2}}$ & $\mathbf{M}_{\mathbf{3}} \mathbf{X}_{\mathbf{2}} \mathbf{O}_{\mathbf{2}}$ & $\mathbf{M}_{\mathbf{4}} \mathbf{X}_{\mathbf{3}} \mathbf{O}_{\mathbf{2}}$ \\
\hline $\mathbf{C}$ & $\mathbf{T i}$ & 1.24 & 2.51 & 3.71 & 1.18 & 1.82 & 3.20 \\
& $\mathbf{Z r}$ & 1.46 & 2.68 & 3.91 & 1.45 & 2.20 & 3.70 \\
& $\mathbf{H f}$ & 1.58 & 2.90 & 4.27 & 1.61 & 2.31 & 3.93 \\
& $\mathbf{V}$ & 0.88 & 2.00 & 2.73 & 0.59 & 0.76 & 1.48 \\
& $\mathbf{N b}$ & 0.69 & 1.46 & 2.15 & 0.96 & 1.19 & 1.95 \\
& $\mathbf{T a}$ & 0.84 & 1.67 & 2.63 & 0.99 & 1.17 & 1.90 \\
& $\mathbf{C r}$ & $\mathbf{0 . 0 0}$ & $\mathbf{0 . 0 1}$ & $\mathbf{- 0 . 2 7}$ & $\mathbf{- 1 . 0 5}$ & $\mathbf{- 1 . 4 9}$ & $\mathbf{- 1 . 8 5}$ \\
& $\mathbf{M o}$ & $\mathbf{- 0 . 2 9}$ & $\mathbf{- 0 . 6 0}$ & $\mathbf{- 1 . 0 5}$ & $\mathbf{- 1 . 5 2}$ & $\mathbf{- 2 . 3 7}$ & $\mathbf{- 2 . 9 5}$ \\
& $\mathbf{W}$ & $\mathbf{- 0 . 4 6}$ & $\mathbf{- 1 . 3 4}$ & $\mathbf{- 2 . 5 6}$ & $\mathbf{- 2 . 3 3}$ & $\mathbf{- 3 . 5 1}$ & $\mathbf{- 4 . 6 9}$ \\
\hline $\mathbf{N}$ & $\mathbf{T i}$ & 0.90 & 1.64 & 2.50 & 0.87 & 0.78 & 1.52 \\
& $\mathbf{Z r}$ & 0.84 & 1.47 & 2.31 & 1.06 & 1.10 & 1.89 \\
& $\mathbf{H f}$ & 0.89 & 1.59 & 2.55 & 1.15 & 1.17 & 1.97 \\
& $\mathbf{V}$ & 0.23 & $\mathbf{- 0 . 0 2}$ & $\mathbf{- 0 . 3 0}$ & $\mathbf{- 0 . 0 1}$ & $\mathbf{- 0 . 3 7}$ & $\mathbf{- 0 . 7 6}$ \\
& $\mathbf{N b}$ & $\mathbf{- 0 . 0 3}$ & $\mathbf{- 0 . 5 3}$ & $\mathbf{- 0 . 9 5}$ & $\mathbf{0 . 0 4}$ & $\mathbf{- 0 . 5 4}$ & $\mathbf{- 0 . 7 8}$ \\
& $\mathbf{T a}$ & $\mathbf{- 0 . 1 9}$ & $\mathbf{- 0 . 8 1}$ & $\mathbf{- 1 . 5 2}$ & $\mathbf{- 0 . 0 1}$ & $\mathbf{- 0 . 7 8}$ & $\mathbf{- 1 . 2 1}$ \\
& $\mathbf{C r}$ & $\mathbf{- 0 . 1 9}$ & $\mathbf{- 0 . 8 8}$ & $\mathbf{- 1 . 5 3}$ & $\mathbf{- 1 . 1 3}$ & $\mathbf{- 1 . 7 2}$ & $\mathbf{- 2 . 3 2}$ \\
& $\mathbf{M o}$ & $\mathbf{- 0 . 2 9}$ & $\mathbf{- 0 . 7 7}$ & $\mathbf{- 1 . 0 9}$ & $\mathbf{- 1 . 2 8}$ & $\mathbf{- 1 . 4 9}$ & $\mathbf{- 1 . 9 0}$ \\
& $\mathbf{W}$ & $\mathbf{- 0 . 3 8}$ & $\mathbf{- 0 . 8 6}$ & $\mathbf{- 1 . 1 0}$ & $\mathbf{- 1 . 3 0}$ & $\mathbf{- 1 . 4 2}$ & $\mathbf{- 1 . 8 9}$ \\
\hline
\end{tabular}




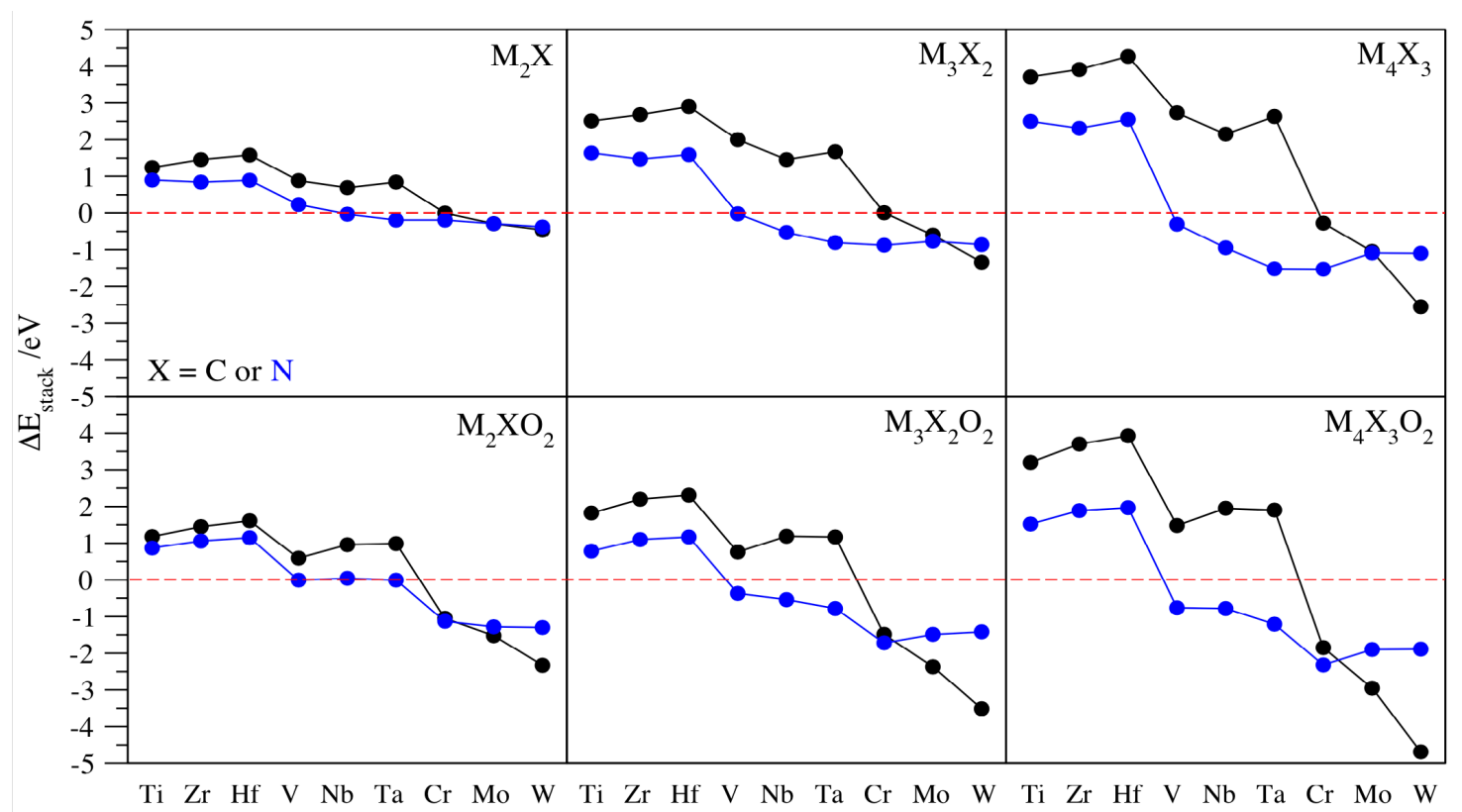

Figure 2. Plots of $\Delta E_{\text {stack }}$ as a function of the $\mathrm{M}$ element for several MXene widths, $n, \mathrm{X}$ compositions $-\mathrm{C}$ in black, $\mathrm{N}$ in blue-, with and without $\mathrm{O}$ termination. The dashed red line denotes the equal energetic stability of $\mathrm{ABC}$ and $\mathrm{ABA}$ stacking, with negative values indicating preference for the latter.

The above trends are very similar when the MXene surfaces are terminated by oxygen, but generally considerably strengthening the ABA stacking, as shown in Table 2 and Figure 2. In fact, nearly all $\Delta E_{\text {stack }}$ values for the O-terminated MXenes in Table 2 are smaller than those of clean systems. As seen in Figure 2, the O-termination greatly stabilizes ABA stacking on group VI $\mathrm{M}_{n+1} \mathrm{X}_{n} \mathrm{O}_{2}$ MXenes, with $\Delta E_{\text {stack }}$ becoming even more negative, by differences between -0.79 to $-2.17 \mathrm{eV}$ per formula unit. Note, however, that the formula unit is different for each stoichiometry and, hence, comparison should be restricted to a given family of MXenes. From this energetic analysis it becomes clear that the ABA stacking preference is enhanced when $i$ ) the number of $d$ electrons of the metal increases, ii) $\mathrm{N}$ is present instead of $\mathrm{C}$, i.e. the number of $\mathrm{X} p$ electrons increases, and/or iii) the MXenes are O-covered, regarded as an electron-rich $\mathrm{T}_{x}$ termination, altogether suggesting that $\mathrm{ABA}$ stacking is fostered by a higher electronic density of the material. These conclusions are in line with the experimentally observed ABA stackings on $\mathrm{Mo}_{2} \mathrm{~N}$ [20], and the previously reported $\mathrm{ABA}$ energetic preferences for $\mathrm{W}_{2} \mathrm{C}, \mathrm{Cr}_{2} \mathrm{~N}$, and $\mathrm{Mo}_{2} \mathrm{C}$ [29]. Note also that, although the present results corroborate the stability of $\mathrm{ABA} \mathrm{Mo}_{2} \mathrm{C}$ or $\mathrm{Mo}_{2} \mathrm{CO}_{2}$ on the hydrogen evolution reaction, as posed by $\mathrm{Lv}$ and coworkers [21], their proposal of preferential ABA stacking for $\mathrm{Ti}_{2} \mathrm{C}, \mathrm{Nb}_{2} \mathrm{C}, \mathrm{V}_{2} \mathrm{C}$, and $\mathrm{Ti}_{3} \mathrm{C}_{2}-$ or their O-terminated versions, $\mathrm{Ti}_{2} \mathrm{CO}_{2}, \mathrm{Nb}_{2} \mathrm{CO}_{2}, \mathrm{~V}_{2} \mathrm{CO}_{2}$, and $\mathrm{Ti}_{3} \mathrm{C}_{2} \mathrm{O}_{2}-$ is not supported by the present calculated data. Even though such structures have been proven to be dynamically stable over 3 ps ab initio 
molecular dynamics runs, the present results clearly show that, for these MXenes, the ABC stacking phases are energetically favorable so that long enough molecular dynamics runs would eventually lead to the lowest $\mathrm{ABC}$ structure. A critical point here is whether the adoption of an ABA stacking would be kinetically inhibited, especially when such MXenes are generated from ABC-stacked MAX phases. In order to address the possible kinetic inhibition for the $\mathrm{ABC} \rightarrow \mathrm{ABA}$ phase transition, the conversion energy barriers, $E_{\mathrm{b}}$, were calculated for the MXenes which displayed energetic preference towards $\mathrm{ABA}$, i.e. $\Delta E_{\text {stack }}<0$. The corresponding values for pristine $\mathrm{M}_{n} \mathrm{X}_{n+1}$ MXenes are reported in Table 3. For $n=1$, the mechanism involves only a simple $\mathrm{C} \rightarrow \mathrm{A}$ sliding. However, for $n \geq 2$, the transition from $\mathrm{ABC}$ to $\mathrm{ABA}$ occurs in several steps, involving the lateral sliding of a few layers, and the values shown in Table 3 correspond to the highest energy barrier among all the considered steps, acting as the ratelimiting energy step. Figure 3 shows examples for $n=1-3 ; \mathrm{W}_{2} \mathrm{C}, \mathrm{W}_{3} \mathrm{C}_{2}$, and $\mathrm{W}_{4} \mathrm{C}_{3}$, showing a guide to all the contemplated sliding steps, given that other MXenes follow similar mechanisms.

Let us analyze the exemplary $\mathrm{W}_{2} \mathrm{C}, \mathrm{W}_{3} \mathrm{C}_{2}$, and $\mathrm{W}_{4} \mathrm{C}_{3}$ cases in fine detail. On $\mathrm{W}_{2} \mathrm{C}$, the transition from $\mathrm{ABC}$ to $\mathrm{ABA}$ stacking (top row of Fig. 3) implies a single exothermic step. On $\mathrm{W}_{3} \mathrm{C}_{2}$, the $\mathrm{ABCAB}$ transition to $\mathrm{ABABA}$ stacking (middle row of Fig. 3) implies three exothermic steps; the first two align the outer $\mathrm{W}$ layers with the inner one, while the last one aligns the remaining $C$ layers with each other. Lastly, the $\mathrm{W}_{4} \mathrm{C}_{3}$ transition from $\mathrm{ABCABCA}$ to ABABABA stacking comprises five steps (bottom row of Fig. 3); the first two are exothermic and align an outer $\mathrm{W}$ layer and its adjacent $\mathrm{C}$ layer with the inner closer $\mathrm{W}$ and $\mathrm{C}$ layers, respectively. The third step is highly exothermic, $\Delta E=-1.08 \mathrm{eV}$ per $\mathrm{W}_{4} \mathrm{C}_{3}$ unit, and aligns the other outer W layer with its closest W layer. After this step, the stacking is CACABAB, which is none other than two ABA-stacked $\mathrm{W}_{2} \mathrm{C}$ surfaces glued by a layer of carbon. This stacking is very stable and, for this reason, the step that follows, that is, the sliding of the first outer $\mathrm{W}$ layer to become aligned with the two farthest $\mathrm{W}$ layers is endothermic, $\Delta E=0.48 \mathrm{eV}$ per $\mathrm{W}_{4} \mathrm{C}_{3}$ unit, making this the highest-barrier step in the process, with an $E_{\mathrm{b}}$ of $1.12 \mathrm{eV}$ per $\mathrm{W}_{4} \mathrm{C}_{3}$ unit. The last step aligns the last $\mathrm{W}$ layer with the other three, and the final ABABABA stacking is achieved, with a global $\Delta E_{\text {stack }}$ of $-2.56 \mathrm{eV}$ per $\mathrm{W}_{4} \mathrm{C}_{3}$ unit. Note that the sliding of the outer $\mathrm{W}$ layers normally implies low $E_{\mathrm{b}}$ values, in between 0.49 and $0.62 \mathrm{eV}$ per $\mathrm{W}_{4} \mathrm{C}_{3}$ unit, whereas the inner $\mathrm{W}$ or $\mathrm{C}$ layers slides require surmounting larger $E_{\mathrm{b}}$ values, between 0.69 and $1.10 \mathrm{eV}$, again per $\mathrm{W}_{4} \mathrm{C}_{3}$ unit. The sole exception is the aforementioned realignment of the outer $\mathrm{W}$ layer in $\mathrm{W}_{4} \mathrm{C}_{3}$, as here the outer $E_{\mathrm{b}}$ of $1.12 \mathrm{eV}$ per $\mathrm{W}_{4} \mathrm{C}_{3}$ unit is clearly biased by the positive $\Delta E=0.48 \mathrm{eV}$ per $\mathrm{W}_{4} \mathrm{C}_{3}$ unit, likely due to the breaking of two C-glued $\mathrm{ABA} \mathrm{W}_{2} \mathrm{C}$ units.

From the values in Table 3, it is clear that the $\mathrm{ABC} \rightarrow \mathrm{ABA}$ conversion is actually not inhibited at all in many cases (see e.g. the $\mathrm{Mo}_{2} \mathrm{~N}, \mathrm{Mo}_{3} \mathrm{~N}_{2}$, and $\mathrm{W}_{2} \mathrm{~N}$ cases, with $E_{\mathrm{b}}$ values of 0.12 $\mathrm{eV}$ per formula unit), and a rapid conversion towards the energetically more stable ABA 
stacking is to be expected. The global observed trend is that the phase transition energy barrier increases with the MXene thickness, i.e. with $n$, surpassing $1 \mathrm{eV}$ per formula unit on $\mathrm{M}_{4} \mathrm{C}_{3}$ and $\mathrm{W}_{3} \mathrm{C}_{2}$. Interestingly, while the $\mathrm{W}_{n+1} \mathrm{C}_{n}$ family displays the largest preference for $\mathrm{ABA}$ stacking among all MXenes, $\mathrm{W}_{3} \mathrm{C}_{2}$ and $\mathrm{W}_{4} \mathrm{C}_{3}$ also exhibit some of the highest energy barriers to reach that atomic structure, suggesting a possible kinetic hindrance. Nevertheless, the energy barrier values are not as high as to become insurmountable at working catalytic operando conditions between 400 and $700 \mathrm{~K}$ although the time scale may be an issue.

Table 3. Calculated $\mathrm{ABC} \rightarrow \mathrm{ABA}$ stacking phase transition energy barriers, $E_{\mathrm{b}}$, in $\mathrm{eV}$ per formula unit, for the studied $\mathrm{M}_{n+1} \mathrm{X}_{n}$ MXenes.

\begin{tabular}{ccccccc}
\hline $\boldsymbol{E}_{\mathbf{b}}$ & & $\mathbf{M}_{n+1} \mathbf{C}_{\boldsymbol{n}}$ & $\mathbf{3}$ & $\mathbf{M}_{\boldsymbol{n}+\mathbf{1}} \mathbf{N}_{\boldsymbol{n}}$ & \\
$\boldsymbol{n}$ & $\mathbf{1}$ & $\mathbf{2}$ & $\mathbf{3}$ & $\mathbf{1}$ & $\mathbf{2}$ & $\mathbf{3}$ \\
\hline \hline $\mathbf{T i}$ & - & - & - & - & - & - \\
$\mathbf{Z r}$ & - & - & - & - & - & - \\
$\mathbf{H f}$ & - & - & - & - & - & - \\
$\mathbf{V}$ & - & - & - & - & 0.72 & 0.91 \\
$\mathbf{N b}$ & - & - & - & 0.64 & 0.54 & 0.72 \\
$\mathbf{T a}$ & - & - & - & 0.53 & 0.52 & 0.70 \\
$\mathbf{C r}$ & 0.72 & 0.88 & 1.04 & 0.33 & 0.32 & 0.69 \\
$\mathbf{M o}$ & 0.52 & 0.93 & 1.22 & 0.12 & 0.12 & 0.51 \\
$\mathbf{W}$ & 0.49 & 1.10 & 1.12 & 0.12 & 0.26 & 0.77 \\
\hline
\end{tabular}

To investigate the effect of the surface termination on the relative kinetic stability of $\mathrm{ABC}$ and $\mathrm{ABA}$ stackings, we consider the case where both sides of the surfaces are fully covered by oxygen. The $E_{\mathrm{b}}$ values for the $\mathrm{ABC} \rightarrow \mathrm{ABA}$ phase transition on O-terminated MXenes are encompassed in Table 4, and are, generally, lower than on the pristine MXene counterparts, as one might well predict regarding the enhanced energetic preference towards ABA, as observed in Table 2. In the case of $\mathrm{M}_{2} \mathrm{XO}_{2}$, the phase transition generally involves two steps: the realignment of the $\mathrm{M} / \mathrm{X}$ layers from $\mathrm{ABC}$ to $\mathrm{ABA}$, and the posterior repositioning of the $\mathrm{O}$ atoms into their ground state adsorption site $-\mathrm{H}_{\mathrm{X}}$ on nearly all MXenes. The exception to the general trend is $\mathrm{W}_{2} \mathrm{NO}_{2}$, which prefers a mixed structure with one layer of $\mathrm{O}$ on $\mathrm{H}_{\mathrm{N}}$ and with the other $\mathrm{O}$ layer on an $\mathrm{H}$ site, $c f$. Figure 1. For comparative purposes, the values shown in Table 4 refer to the highest energy barrier per formula unit among the steps of the realignment of the $\mathrm{M} / \mathrm{X}$ layers only. Nevertheless, in general terms, the energy barriers for surface $\mathrm{O}$ relocation are rather high, between 0.5 and $1.1 \mathrm{eV}$ per formula unit, yet still surmountable depending on the operando conditions, see the example of $\mathrm{Cr}_{2} \mathrm{CO}_{2}$ in Figure 4. Comparing the $E_{\mathrm{b}}$ values of Tables 3 and 4 , one readily notices that the O-termination usually reduces the energy barriers by a few tenths of $\mathrm{eV}$. This is understandable, as the presence of $\mathrm{O}$ on the surface weakens the bonds between the outer metal atoms and the inner $\mathrm{X}$ layer atoms, allowing 
for energetically easier layer sliding. On $\mathrm{Mo}_{2} \mathrm{NO}_{2}$, the realignment barrier is only $0.12 \mathrm{eV}$ per formula unit. This, together with the relative energetic stability, $1.28 \mathrm{eV}$ per formula unit in favor for ABA stacking, further justifies the experimental observation of a nitride phase with a different layer stacking than the precursor. ${ }^{20}$
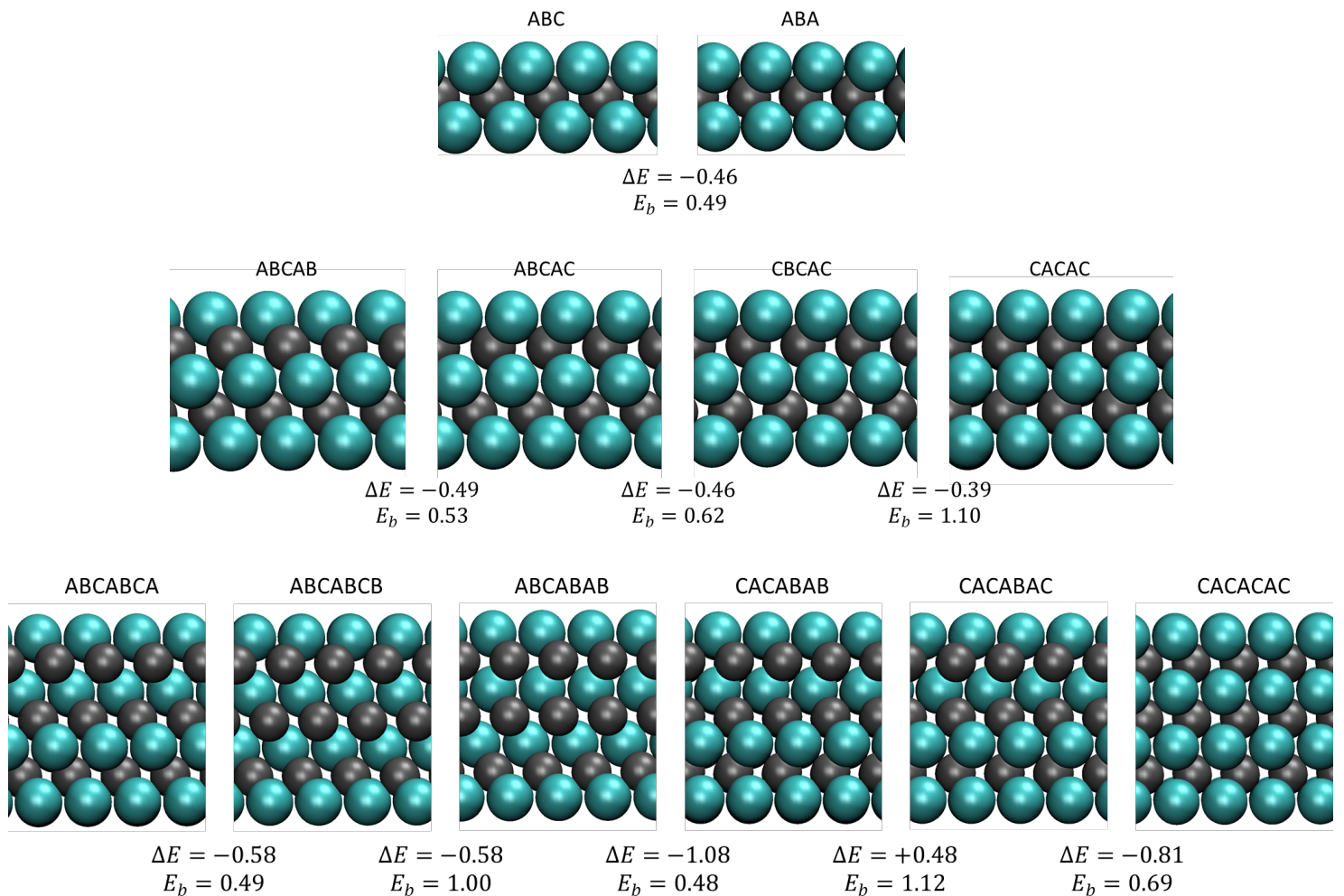

Figure 3. Side views of the sliding steps taken by the $\mathrm{W}_{2} \mathrm{C}$ (top), $\mathrm{W}_{3} \mathrm{C}_{2}$ (middle), and $\mathrm{W}_{4} \mathrm{C}_{3}$ (bottom) MXene surfaces in their transition from $\mathrm{ABC}$ to $\mathrm{ABA}$ stacking. Below each transition step, the values of the reaction step energy change, $\Delta \mathrm{E}$, and its energetic barrier, $E_{\mathrm{b}}$, are given in $\mathrm{eV}$ and per formula unit.
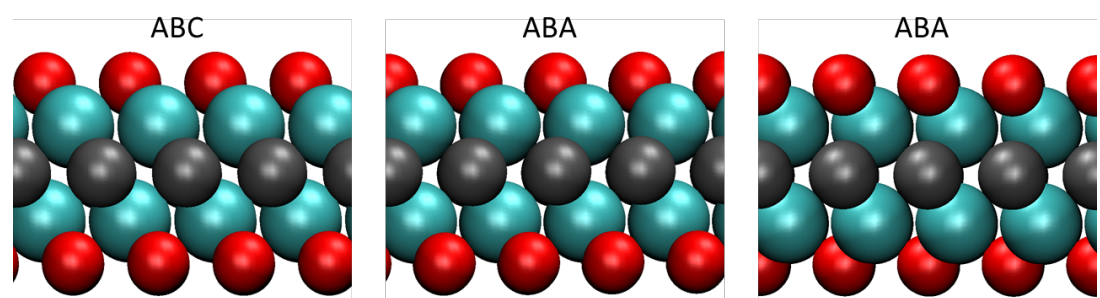

$$
\begin{array}{cc}
\Delta E=-0.78 & \Delta E=-0.27 \\
E_{b}=0.09 & E_{b}=0.90
\end{array}
$$

Figure 4. Side view of the sliding steps taken by $\mathrm{Cr}_{2} \mathrm{CO}_{2}$ MXene surface during its $\mathrm{ABC} \rightarrow \mathrm{ABA}$ stacking transition. Below each transition step, the values of the reaction step energy change, $\Delta \mathrm{E}$, and its energetic barrier, $E_{\mathrm{b}}$, are given in $\mathrm{eV}$. 
Table 4. Calculated $\mathrm{ABC} \rightarrow \mathrm{ABA}$ stacking phase transition energy barriers, $E_{\mathrm{b}}$, in $\mathrm{eV}$ per formula unit, for the studied fully O-covered $\mathrm{M}_{n+1} \mathrm{X}_{n} \mathrm{O}_{2}$ MXenes.

\begin{tabular}{ccccccc}
\hline $\boldsymbol{E}_{\mathbf{b}}$ & & $\mathbf{M}_{n+1} \mathbf{C}_{n} \mathbf{O}_{2}$ & & \multicolumn{3}{c}{$\mathbf{M}_{n+1} \mathbf{N}_{n} \mathbf{O}_{2}$} \\
$\boldsymbol{n}$ & $\mathbf{1}$ & $\mathbf{2}$ & $\mathbf{3}$ & $\mathbf{1}$ & $\mathbf{2}$ & $\mathbf{3}$ \\
\hline \hline $\mathrm{Ti}$ & - & - & - & - & - & - \\
$\mathrm{Zr}$ & - & - & - & - & - & - \\
$\mathrm{Hf}$ & - & - & - & - & - & - \\
$\mathrm{V}$ & - & - & - & 0.53 & 0.59 & 0.71 \\
$\mathrm{Nb}$ & - & - & - & 0.54 & 0.55 & 0.67 \\
$\mathrm{Ta}$ & - & - & - & 0.39 & 0.45 & 0.52 \\
$\mathrm{Cr}$ & 0.09 & 0.55 & 0.72 & 0.13 & 0.12 & 0.44 \\
$\mathrm{Mo}$ & 0.44 & 0.70 & 0.92 & 0.12 & 0.11 & 0.30 \\
$\mathrm{~W}$ & 0.25 & 0.86 & 0.91 & 0.10 & 0.13 & 0.53 \\
\hline
\end{tabular}

Given the low $E_{\mathrm{b}}$ per formula unit values here reported for a series of cases, one may wonder whether $\mathrm{O}$ adsorption could be enough to drive the stacking phase transition. This is exemplified on the $\mathrm{W}_{2} \mathrm{~N}$ system, being known to yield a $D_{3 \mathrm{~h}}$ ABA symmetry [19]. We begin this analysis by covering its $p(3 \times 3)$ supercell with $\mathrm{O}$ adatoms on $\mathrm{H}_{\mathrm{M}}$ sites - the most stable sites for $\mathrm{O}$ adsorption - while the other side is sequentially saturated by $\mathrm{O}$. The simultaneous adsorption energy per oxygen atom, $E_{\text {ads }} / N_{\mathrm{O}}$, was calculated as detailed above, and the stepwise $\mathrm{O}$ adsorption, $E_{\text {ads }}^{\text {step }}$, addressing the MXene continuous oxidation process was obtained as well, as

$$
E_{\mathrm{ads}}^{\text {step }}=E_{N_{\mathrm{O}} / \mathrm{MXene}}-E_{N_{\mathrm{O}}-1 / \mathrm{MXene}}-\frac{E_{\mathrm{O}_{2}}}{2}
$$

The $E_{\text {ads }}^{\text {step }}$ value gives information on the energy released when an MXene containing $N_{\mathrm{O}}-1 \mathrm{O}$ adatoms adsorbs an additional $\mathrm{O}$ atom. The $E_{\text {ads }} / N_{\mathrm{O}}$ and $E_{\text {ads }}^{\text {step values are }}$ encompassed in Table 4, for $\mathrm{W}_{2} \mathrm{~N}$ in either an $\mathrm{ABC}$ or an $\mathrm{ABA}$ configuration. On the one hand, the values of $E_{\text {ads }} / N_{\mathrm{O}}$ in Table 5 are all negative, implying exothermicity, at least until full $\mathrm{O}$ coverage, with values ranging from -3.56 to $-5.08 \mathrm{eV}$ for $\mathrm{ABC}$ stacking, and varying much less, between -4.07 and $-4.27 \mathrm{eV}$, for ABA stacking. On the other hand, the $E_{\text {ads }}^{\text {step }}$ values are always negative as well, but on $\mathrm{ABC}$ stacking largely oscillate between $-1.67 \mathrm{eV}$ and $-7.09 \mathrm{eV}$. Such fringe situations can be understood when the system symmetry is accounted for as $N_{\mathrm{O}}$ increases. Indeed, the stepwise adsorption is stronger whenever the symmetry is reduced from $C_{3 \mathrm{v}}$ to $C_{1 \mathrm{~h}}$ by adsorbing the extra $\mathrm{O}$ atom. This situation is not observed on the ABA stacking, with $E_{\text {ads }}^{\text {step }}$ values ranging between -3.69 and $-4.30 \mathrm{eV}$, as the surface is kept intact during the $\mathrm{O}$ coverage. 
Table 5. Adsorption energy per $\mathrm{O}$ atom, $E_{\text {ads }} / N_{\mathrm{O}}$, and stepwise adsorption energy, $E_{\text {ads }}^{\text {step }}$, on the $\mathrm{W}_{2} \mathrm{~N}$ MXene with $\mathrm{ABC}$ or $\mathrm{ABA}$ stacking configurations.

\begin{tabular}{c|ccc|cc}
\hline \multirow{2}{*}{$N_{\mathrm{O}}$} & \multicolumn{3}{|c|}{$\mathrm{ABC}$} & \multicolumn{2}{c}{$\mathrm{ABA}$} \\
& Symmetry & $E_{\text {ads }} / N_{\mathrm{O}}$ & $E_{\text {ads }}^{\text {step }}$ & $E_{\text {ads }} / N_{\mathrm{O}}$ & $E_{\text {ads }}^{\text {step }}$ \\
\hline \hline 0 & $C_{3 \mathrm{v}}$ & ---- & ---- & ---- & ---- \\
1 & $C_{3 \mathrm{v}}$ & -3.56 & -3.56 & -4.24 & -4.24 \\
2 & $C_{1 \mathrm{~h}}$ & -5.08 & -6.59 & -4.27 & -4.30 \\
3 & $C_{3 \mathrm{v}}$ & -4.02 & -1.92 & -4.24 & -4.18 \\
4 & $C_{1 \mathrm{~h}}$ & -4.79 & -7.09 & -4.23 & -4.20 \\
5 & $C_{1 \mathrm{~h}}$ & -4.19 & -1.78 & -4.20 & -4.07 \\
6 & $C_{3 \mathrm{v}}$ & -3.77 & -1.67 & -4.19 & -4.12 \\
7 & $C_{1 \mathrm{~h}}$ & -3.89 & -4.60 & -4.15 & -3.94 \\
8 & $C_{3 \mathrm{v}}$ & -3.69 & -2.35 & -4.11 & -3.86 \\
9 & $D_{3 \mathrm{~d}}$ & -3.58 & -2.62 & -4.07 & -3.69 \\
\hline
\end{tabular}

The strongest $E_{\text {ads }}^{\text {step }}$ values are associated to a surface relaxing effect observed on the MXene surface. As shown in Figure 5 for the initial $\mathrm{O}$ adsorptions with $N_{\mathrm{O}}=0-2$, when the symmetry is $C_{1 \mathrm{~h}}$, the lattice becomes largely distorted, and the apparent stronger $E_{\mathrm{ads}}^{\text {step }}=-6.59$ $\mathrm{eV}$ is not due solely to the $\mathrm{O}$ adsorption itself, but in part due to the surface relaxation it promotes. The symmetry reduction caused by the adsorption seems to already reduce the energy barrier required by the $\mathrm{W}_{2} \mathrm{~N}$ surface to relax into a more stable configuration. This explains the oscillation between small and large $E_{\text {ads }}^{\text {step }}$ alongside the $C_{3 \mathrm{v}}$ and $C_{1 \mathrm{~h}}$ symmetries. This conclusion was confirmed by repeating the calculations, but breaking the symmetry of the system, making it $C_{1}$. Similar oscillations to the ones in Table 2 were obtained, yet for the last $\mathrm{O}$ adsorption, an $E_{\text {ads }}^{\text {step }}$ of very high absolute value of $-12.77 \mathrm{eV}$ was obtained, not corresponding to the sole $\mathrm{O}$ adsorption, but being mostly the result of the MXene layer realignment upon conversion of the $\mathrm{ABC}$ stacking into the $\mathrm{ABA}$ one, highlighting how the strong $\mathrm{O}$ adsorptions are enough to surmount the almost insignificant $E_{\mathrm{b}}$ values. Note that the positions occupied by the $\mathrm{O}$ atoms are not the same on both sides of the MXene after the transition to ABA: $\mathrm{O}$ is placed over $\mathrm{H}$ sites on one side, and over $\mathrm{H}_{\mathrm{N}}$ sites on the other side, see Figure 6, in line with the above results. This placement of the $\mathrm{O}$ atoms is preferred over pure $\mathrm{H}_{\mathrm{N}}$ or $\mathrm{H}$ by 0.05 and $0.54 \mathrm{eV}$ per unit supercell, respectively. 

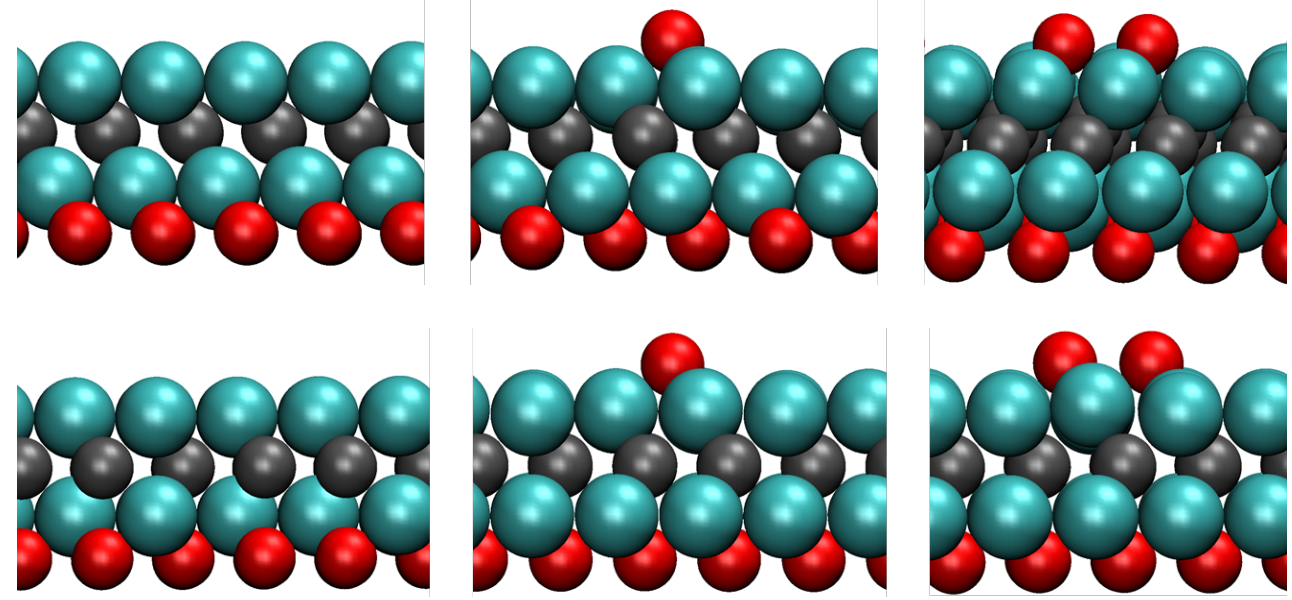

Figure 5. Side views of the optimized $\mathrm{W}_{2} \mathrm{NO}_{\mathrm{x}}$ MXene (0001) surface, with $\mathrm{ABC}$ (top) or ABA (bottom) stacking, and with $N_{\mathrm{O}}=0$ (left), $N_{\mathrm{O}}=1$ (middle), both with $C_{3 \mathrm{v}}$ symmetry, and $N_{\mathrm{O}}=2$ (right), with $C_{1 \mathrm{~h}}$ symmetry. Note the severe surface distortion that occurs when $\mathrm{W}_{2} \mathrm{~N}$ with $\mathrm{ABC}$ stacking and one surface fully $\mathrm{O}$-covered, adsorbs two $\mathrm{O}$ atoms on the other side.
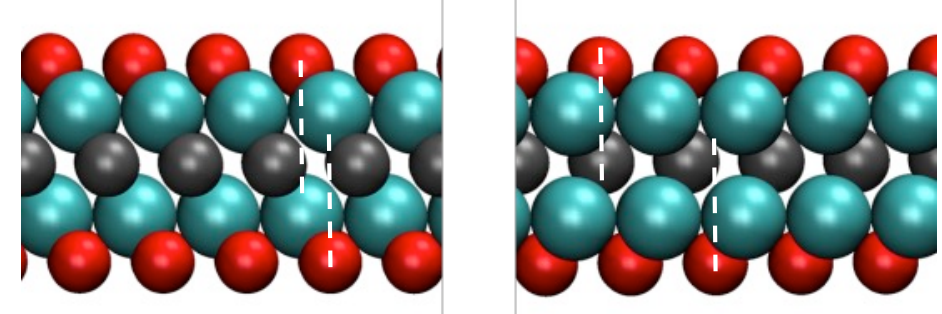

Figure 6. Side views of a $\mathrm{W}_{2} \mathrm{NO}_{2}$ MXene surface with $\mathrm{ABC}$ (left) and $\mathrm{ABA}$ (right) stacking. Dashed lines are guides to the eye; notice the asymmetry of the hollow sites occupied by the $\mathrm{O}$ atoms in the case of ABA.

Following the previous discussion, the question of whether ABA stacking is more stable for any $\mathrm{O}$ coverage arises. From Figure 2, it is clear that the ABA stacking is more favorable for $\mathrm{W}_{2} \mathrm{~N}$ both as pristine and fully O-covered, and the small $E_{\mathrm{b}}$ of the pristine $\mathrm{W}_{2} \mathrm{~N}$ of 0.12 per formula unit would indicate that the energetic release by the adsorption of a moiety would actually be enough to overcome such a barrier. To further illustrate this point, the calculated $T / p_{\mathrm{O}_{2}}$ phase diagram of oxygen coverage of $\mathrm{W}_{2} \mathrm{~N}$ is shown in Figure 7. Each point of the diagram displays the situation with lowest $G_{\text {ads }}$. This is exemplified e.g. on the left panel of this Figure for a fixed pressure of 1 bar $\left(10^{5} \mathrm{~Pa}\right)$, and different surface $\mathrm{O}$ coverage situations as a function of the temperature. Inspection of Figure 7 reveals that an O-free situation at 1 bar is only attainable at an extreme $T$ above $\sim 2200 \mathrm{~K}$. The transition region between the fully O- 
covered situation, and the pristine MXene is very narrow, as seen in the phase diagram of Figure 7, and one should regard such MXenes as O-covered at normal $\mathrm{O}_{2}$ partial pressures, yet O-free surfaces are attainable at ultra-high-vacuum conditions and high temperatures, e.g. below $10^{-8} \mathrm{~Pa}$ and $T \sim 800 \mathrm{~K}$, although there exist O-cleaning protocols by annealing and hydrogenation steps [5].
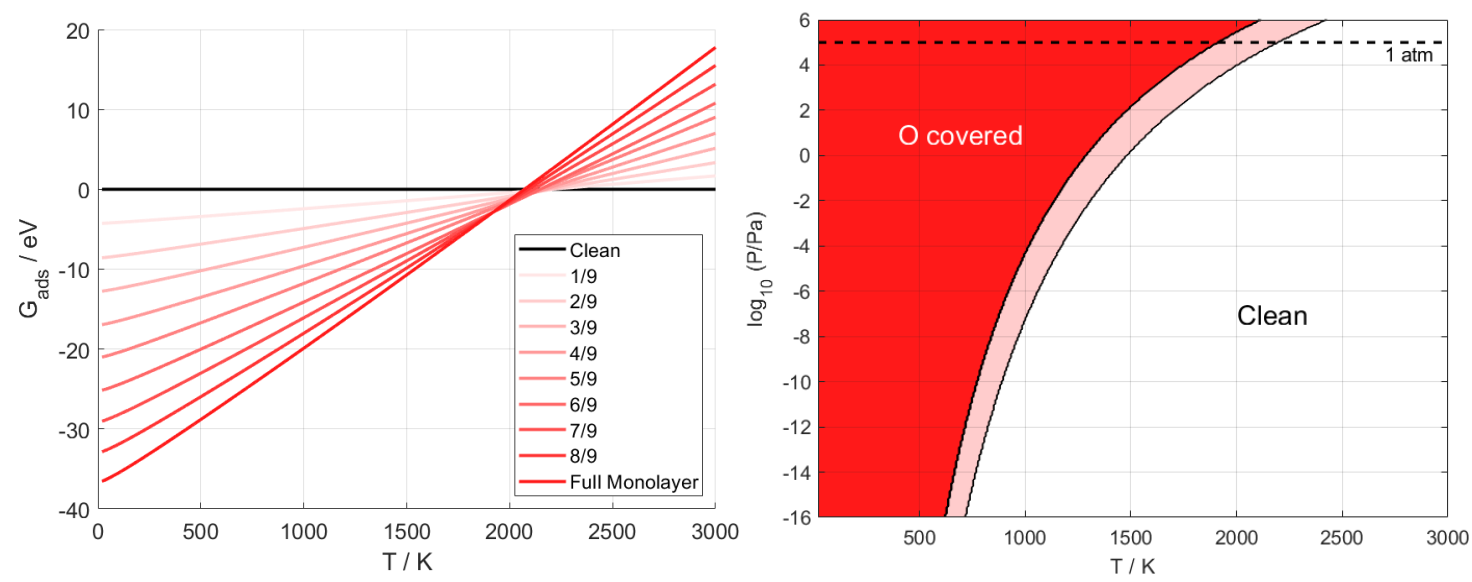

Figure 7. Gibbs free adsorption energies, $G_{\text {ads }}$, as a function of temperature, $T$, for each fraction of $\mathrm{O}$ coverage (from the clean surface in black to the full monolayer of $\mathrm{O}$ adatoms in red), at a constant pressure of 1 bar (left). The $T / p_{\mathrm{O}_{2}}$ phase diagram (right) showing the oxidation transition zone (pink) for $\mathrm{W}_{2} \mathrm{~N}$, separating the pristine (white area) and the fully covered (red) surface regions.

Once the relative stability of the $\mathrm{ABC}$ and $\mathrm{ABA}$ stackings has been clarified for the scrutinized MXenes, there is still the question regarding the possible effect of the stacking on the chemical reactivity of the MXene surfaces. To answer that question, we studied the atomic $\mathrm{N}$ adsorption and molecular $\mathrm{N}_{2}$ adsorption and dissociation, technologically relevant in the Haber-Bosch ammonia synthesis [22], on the eight clean $\mathrm{M}_{2} \mathrm{X}$ where ABA stacking is preferred. Table 5 reports the $\mathrm{N}_{2}$ adsorption energies, $E_{\text {ads }}^{\mathrm{N}_{2}}$, the $\mathrm{N}$ adatom adsorption energies, $E_{\text {ads }}^{N}$, with respect to $1 / 2 \cdot \mathrm{N}_{2}$, the $\mathrm{N}_{2}$ dissociation energy barrier, $E_{\mathrm{b}}^{\mathrm{N}_{2}}$, and the reaction step energy change, $E_{\text {reaction }}^{\mathrm{N}_{2} \rightarrow 2 \mathrm{~N}}$, when occurring either on the $\mathrm{ABC}$ or the ABA stacking conformations. The results reveal changes in adsorption energies that can be in some cases negligible, of $0.01 \mathrm{eV}$ for $\mathrm{N}$ adsorption on $\mathrm{Mo}_{2} \mathrm{~N}$ and $\mathrm{W}_{2} \mathrm{~N}$, to noticeable, of almost $1 \mathrm{eV}$ for $\mathrm{N}_{2}$ adsorption on $\mathrm{Nb}_{2} \mathrm{~N}$. The impact on the reaction energy changes ranges between 0.03 and $0.70 \mathrm{eV}$. Some $\mathrm{N}_{2}$ dissociation energy barriers remained unchanged, while others varied by up to around $0.3 \mathrm{eV} . \mathrm{Nb}_{2} \mathrm{~N}$ is the only case where the $\mathrm{N}_{2}$ dissociation barrier is found to be higher with ABA than with $A B C$ 
alignment. Lastly, we calculated the energy barriers for the triple hydrogenation of an $\mathrm{N}$ adatom on $\mathrm{W}_{2} \mathrm{~N}$ to form $\mathrm{NH}_{3}$ for both $\mathrm{ABC}$ and $\mathrm{ABA}$ stacking. For the $\mathrm{ABC}$-stacked $\mathrm{W}_{2} \mathrm{~N}$ the calculated values are 1.24, 1.70, and $1.69 \mathrm{eV}$ whereas for the ABA stacking of $\mathrm{W}_{2} \mathrm{~N}$ these values change to $0.85,1.21$ and $1.72 \mathrm{eV}$, thus greatly facilitating the first two hydrogenations, reducing the barriers by 0.39 and $0.51 \mathrm{eV}$, while the third is merely heightened by $0.03 \mathrm{eV}$. Thus, it appears that the impact of stacking on a reaction profile can be significant, with adsorption strengths changes up to $c a .1 \mathrm{eV}$, and energy barrier changes of up to $\sim 0.3 \mathrm{eV}$, which can signify changes in the reaction step rate constant of up to three or four orders of magnitude in the temperature range of $400-700 \mathrm{~K}$. Consequently, and to avoid unduly model-biased artifacts in computed results, the use of the correct stacking conformation under working operando conditions is strongly advised.

Table 5. $\mathrm{N}$ and $\mathrm{N}_{2}$ adsorption energies, $E_{\text {ads }}^{N}$ and $E_{\text {ads }}^{\mathrm{N}_{2}}$, respectively, $\mathrm{N}_{2}$ dissociation energy barriers, $E_{\mathrm{b}}^{\mathrm{N}_{2}}$, and $\mathrm{N}_{2} \rightarrow 2 \mathrm{~N}$ reaction step energy change, $E_{\text {reaction }}^{\mathrm{N}_{2} \rightarrow 2 \mathrm{~N}}$, on the $\mathrm{M}_{2} \mathrm{X}$ MXenes with preference towards ABA stacking. All values are given in eV and include ZPE corrections.

\begin{tabular}{c|cccc|cccc}
\hline \multirow{2}{*}{ MXene } & \multicolumn{4}{|c|}{ ABC stacking } & \multicolumn{4}{c}{ ABA stacking } \\
\cline { 2 - 9 } & $E_{\text {ads }}^{N}$ & $E_{\text {ads }}^{\mathrm{N}_{2}}$ & $E_{\mathrm{b}}^{\mathrm{N}_{2}}$ & $E_{\text {reaction }}^{\mathrm{N}_{2} \rightarrow 2 \mathrm{~N}}$ & $E_{\text {ads }}^{N}$ & $E_{\text {ads }}^{\mathrm{N}_{2}}$ & $E_{\mathrm{b}}^{\mathrm{N}_{2}}$ & $E_{\text {reaction }}^{\mathrm{N}_{2} \rightarrow 2 \mathrm{~N}}$ \\
\cline { 2 - 9 } $\mathrm{Cr}_{2} \mathrm{C}$ & -2.01 & -2.12 & 0.85 & -1.90 & -1.71 & -2.06 & 0.78 & -1.37 \\
$\mathrm{Mo}_{2} \mathrm{C}$ & -1.97 & -1.59 & 0.93 & -2.35 & -1.76 & -1.36 & 0.62 & -2.16 \\
$\mathrm{~W}_{2} \mathrm{C}$ & -1.79 & -1.11 & 0.37 & -2.48 & -1.84 & -1.14 & 0.37 & -2.53 \\
$\mathrm{Nb}_{2} \mathrm{~N}$ & -2.23 & -1.76 & 0.60 & -2.70 & -2.34 & -2.68 & 0.78 & -2.00 \\
$\mathrm{Ta}_{2} \mathrm{~N}$ & -2.59 & -2.12 & 0.48 & -3.06 & -2.61 & -2.85 & 0.54 & -2.38 \\
$\mathrm{Cr}_{2} \mathrm{~N}$ & -1.76 & -1.66 & 0.61 & -1.85 & -1.94 & -1.99 & 0.61 & -1.89 \\
$\mathrm{Mo}_{2} \mathrm{~N}$ & -2.15 & -1.55 & 0.45 & -2.76 & -2.16 & -1.73 & 0.41 & -2.60 \\
$\mathrm{~W}_{2} \mathrm{~N}$ & -2.26 & -1.34 & 0.28 & -3.19 & -2.25 & -1.27 & 0.18 & -3.22 \\
\hline
\end{tabular}

\section{Conclusions}

A first-principles DFT study including dispersion was carried out for a total of 54 MXene 2D transition metal carbide and nitride materials. The analysis of the results reveals that the ABA type of layer stacking is competitive for a number of cases meaning that the MAX-derived ABC stacking cannot be taken as granted. Energetic data reveal that the ABA stacking appears to be more frequent than anticipated and is fostered by the number of the constituent metal $d$ electrons, preferred by nitride instead of carbide MXenes, and favored by the $\mathrm{O}$ surface termination. The calculated sliding energy barriers for the conversion of $\mathrm{ABC}$ towards $\mathrm{ABA}$ 
reveal very small energy barriers as low as $0.12 \mathrm{eV}$ per formula unit for some MXenes, and higher ones, up to $1.12 \mathrm{eV}$ per formula unit, for thicker $\mathrm{M}_{3} \mathrm{X}_{2}$ and $\mathrm{M}_{4} \mathrm{X}_{3} \mathrm{MXenes,}$ in any case, surmountable at high temperature operando conditions. On $\mathrm{M}_{2} \mathrm{X}$ systems, the adsorption of species or the formation of an $\mathrm{O}$ overlayer can be enough to prompt the conversion from $\mathrm{ABC}$ towards an ABA stacking. This ABA layer stacking was found to influence the adsorption energies and reaction energy barriers of surface on-going processes, with energetic changes that can vary between a few hundredths of $\mathrm{eV}$ to $\sim 1 \mathrm{eV}$, which can definitely bias the reaction profile, even the reaction step rate constants, by up to three or four orders of magnitude in usual working condition temperatures. To summarize, the present study provides compelling evidence that the atomic layer stacking on MXenes can be different from that expected from the MAX phase precursor for nearly half of the studied MXenes, with several important consequences for the MXene surfaces chemistry and, likely, on physical properties as well which call for further analysis. A careful atomic structure determination is advised rather than assuming that corresponding to the parent MAX phase. Computational models should seriously also consider this issue.

\section{Acknowledgements}

The research carried out at the CICECO - University of Aveiro Institute of Materials, was developed within the scope of the projects UIDB/50011/2020 \& UIDP/50011/2020, financed by national funds through the Portuguese Fundação para a Ciência e a Tecnologia (FCT/MEC) and co-financed by FEDER under the PT2020 Partnership Agreement. The research carried out at the Universitat de Barcelona has been supported by the Spanish MICIUN/FEDER RTI2018095460-B-I00 and María de Maeztu MDM-2017-0767 grants and, in part, by Generalitat de Catalunya 2017SGR13 and XRQTC grants. J.D.G. is also thankful to projects CENTRO-010145-FEDER-31002 (SILVIA) and HPC-EUROPA3 (INFRAIA-2016-1-730897) supported by the EC Research Innovation Action under the H2020 Programme. F. I. acknowledges additional support from the 2015 ICREA Academia Award for Excellence in University Research. 


\section{References}

[1] Naguib M, Kurtoglu M, Presser V, Lu J, Niu J, Heon M, Hultman L, Gogotsi Y and Barsoum M W 2011 Two-dimensional nanocrystals produced by exfoliation of $\mathrm{Ti}_{3} \mathrm{AlC}_{2}$ Adv. Mater. 23 4248-53

[2] Naguib M and Gogotsi Y 2015 Synthesis of two-dimensional materials by selective extraction Acc. Chem. Res. 48 128-35

[3] Zhao L, Dong B, Li S, Zhou L, Lai L, Wang Z, Zhao S, Han M, Gao K, Lu M, Xie X, Chen B, Liu Z, Wang X, Zhang H, Li H, Liu J, Zhang H, Huang X and Huang W 2017 Interdiffusion reaction-assisted hybridization of two-dimensional metal-organic frameworks and $\mathrm{Ti}_{3} \mathrm{C}_{2} \mathrm{~T}_{\mathrm{x}}$ nanosheets for electrocatalytic oxygen evolution ACS Nano 11 5800-07

[4] Morales-García A, Fernández-Fernández A, Viñes $\mathrm{F}$ and Illas $\mathrm{F} 2018 \mathrm{CO}_{2}$ abatement using two-dimensional MXene carbides J. Mater. Chem. A 6 3381-85

[5] Persson I, Halim J, Lind H, Hansen T W, Wagner J B, Näslund L $\AA$, Darakchieva V, Palisaitis J, Rosen J and Persson P O $\AA 2019$ 2D transition metal carbides (MXenes) for carbon capture Adv. Mater. 311805472

[6] Lukatskaya M R, Mashtalir O, Ren C E, Dall'Agnese Y, Rozier P, Taberna P L, Naguib M, Simon P, Barsoum M W and Gogotsi Y 2013 Cation intercalation and high volumetric capacitance of two-dimensional titanium carbide Science 341 1502-5

[7] Lu C, Tranca D, Zhang J, Rodríguez Hernández F, Su Y, Zhuang X, Zhang F, Seifert G and Feng X 2017 Molybdenum carbide-embedded nitrogen-doped porous carbon nanosheets as electrocatalysts for water splitting in alkaline media ACS Nano $113933-42$

[8] Gao G, O’Mullane A P and Du A 2017 2D MXenes: a new family of promising catalysts for the hydrogen evolution reaction ACS Catal. 7 494-500

[9] Ma L, Ting L R L, Molinari V, Giordano C and Yeo B S 2015 Efficient hydrogen evolution reaction catalyzed by molybdenum carbide and molybdenum nitride nanocatalysts synthesized via the urea glass route $J$. Mater. Chem. A 3 8361-8

[10] Cao M-S, Cai Y-Z, Cai J-C, He P, Shu J C, Cao W Q and Yuan J 2019 2D MXenes: Electromagnetic property for microwave absorption and electromagnetic interference shielding Chem. Eng. J. 359 1265-302 
[11] Alhabeb M, Maleski K, Mathis T S, Sarycheva A, Hatter C B, Uzun S, Levitt A and Gogotsi Y 2018 Selective etching of silicon from $\mathrm{Ti}_{3} \mathrm{SiC}_{2}$ (MAX) to obtain 2D titanium carbide (MXene) Angew. Chem. Int. Ed. 57 5444-8

[12] Alhabeb M, Maleski K, Anasori B, Lelyukh P, Clark L, Sin S and Gogotsi Y 2017 Guidelines for synthesis and processing of two-dimensional titanium carbide $\left(\mathrm{Ti}_{3} \mathrm{C}_{2} \mathrm{~T}_{\mathrm{x}}\right.$ MXene) Chem. Mater. 29 7633-44

[13] Mashtalir O, Naguib M, Mochalin V N, Dall'Agnese Y, Heon M, Barsoum M W and Gogotsi Y 2013 Intercalation and delamination of layered carbides and carbonitrides Nat. Commun. 41716

[14] Peng J, Chen X, Ong W J, Zhao X and Li N 2019 Surface and heterointerface engineering of 2D MXenes and their nanocomposites: insights into electro- and photocatalysis Chem $\mathbf{5} 18-50$

[15] Li T, Yao L, Liu Q, Gu J, Luo R, Li J, Yan X, Wang W, Liu P, Chen B, Zhang W, Abbas W, Naz R and Zhang D 2018 Fluorine-free synthesis of high-purity $\mathrm{Ti}_{3} \mathrm{C}_{2} \mathrm{~T}_{\mathrm{x}}(\mathrm{T}=\mathrm{OH}, \mathrm{O})$ via alkali treatment Angew. Chem. Int. Ed. 57 6115-9

[16] Guan Y F, Jiang S, Cong Y, Wang J P, Dong Z J, Zhang Q, Yuan G M, Li Y J and Li X K 2020 A hydrofluoric acid-free synthesis of 2D vanadium carbide $\left(\mathrm{V}_{2} \mathrm{C}\right) \mathrm{MXene}$ for supercapacitor electrodes 2D Mater. 7025010

[17] Deysher G, Shuck C E, Hantanasirisakul K, Frey N C, Foucher A C, Maleski K, Sarycheva A, Shenoy V B, Stach E A, Anasori B and Gogotsi Y 2020 Synthesis of $\mathrm{Mo}_{4} \mathrm{VAlC}_{4}$ MAX phase and two-dimensional $\mathrm{Mo}_{4} \mathrm{VC}_{4}$ MXene with five atomic layers of transition metals ACS Nano 14 207-14

[18] Hart J L, Hantanasirisakul K, Lang A C, Anasori B, Pinto D, Pivak Y, Tijn van Omme J, May S J, Gogotsi Y and Taheri M L 2019 Control of MXenes' electronic properties through termination and intercalation Nat. Comm. 10522

[19] Shao M, Shao Y, Chen W, Ao K L, Tong R, Zhu Q, Chan I N, Ip W F, Shi X and Pan H 2018 Efficient nitrogen fixation to ammonia on MXenes Phys. Chem. Chem. Phys. 20 14504-12

[20] Urbankowski P, Anasori B, Hantanasirisakul K, Yang L, Zhang L, Haines B, May S J, Billinge S J E and Gogotsi Y 2017 2D molybdenum and vanadium nitrides synthesized by ammoniation of 2D transition metal carbides (MXenes) Nanoscale 9 17722-30 
[21] Lv H, Wei W, Zhao P, Er E, Huang B, Dai Y and Jacob T 2019 Oxygenterminated BiXenes and derived single atom catalysts for the hydrogen evolution reaction $J$. Catal. 378 97-103

[22] Erisman J W, Sutton M A, Galloway J, Klimont Z and Winiwater W 2008 How a century of ammonia synthesis changed the world Nat. Geosci. 1 636-9

[23] Kresse G and Furthmüller J 1996 Efficient iterative schemes for ab initio totalenergy calculations using a plane-wave basis set Phys. Rev. B 5411169

[24] Perdew J P, Burke K and Ernzerhof M 1996 Generalized gradient approximation made simple Phys. Rev. Lett. 773865

[25] Grimme S, Antony J, Ehrlich S and Krieg H 2010 A consistent and accurate $a b$ initio parametrization of density functional dispersion correction (DFT-D) for the 94 elements H-Pu J. Chem. Phys. 132154104

[26] Blöchl P E 1994 Projector augmented-wave method Phys. Rev. B 5017953

[27] Zhang N, Hong Y, Yazdanparast S and Zaeem M A 2018 Superior structural, elastic and electronic properties of 2D titanium nitride MXenes over carbide MXenes: a comprehensive first principles study 2D Mater. 5045004

[28] Kurtoglu M, Naguib M, Gogotsi Y and Barsoum M W 2012 First principles study of two-dimensional early transition metal carbides MRS Commun. 2 133-7

[29] Sun W, Li Y, Wang B, Jiang X, Katsnelson M I, Korzhavyi P, Eriksson O and Di Marco I 2016 A new 2D monolayer BiXene, $\mathrm{M}_{2} \mathrm{C}(\mathrm{M}=\mathrm{Mo}$, Tc, Os) Nanoscale 8 15753-62

[30] Monkhorst H J and Pack J D 1976 Special points for Brillouin-zone integrations Phys. Rev. B 135188

[31] Henkelman G and Jónsson H 1999 A dimer method for finding saddle points on high dimensional potential surfaces using only first derivatives J. Chem. Phys. 1117010

[32] Rogal J and Reuter K, Experiment, Modeling and Simulation of Gas-Surface Interactions for Reactive Flows in Hypersonic Flights, Educational Notes RTOEN-AVT-142, 2007, 2, 2-1 - 2-18. 